\title{
Erratum to: The Qatari Family at the Intersection of Policies
}

\section{Lina M. Kassem and Esraa Al-Muftah}

Erratum to: The Author(s) 2016

M.E. Tok et al. (eds.), Policy-Making in a Transformative State, DOI 10.1057/978-1-137-46639-6_8

The affiliation was inadvertently published for chapter author Esraa Al-Muftah. The correct affiliation should read as follows:

E. Al-Muftah

University of British Columbia, Canada

Qatar University, Qatar

The updated original online version for this chapter can be found at DOI 10.1057/978-1-137-46639-6_8

L.M. Kassem

Department of International Affairs, Qatar University, Doha, Qatar

E. Al-Muftah

University of British Columbia, Canada

Qatar University, Qatar 